\title{
MORFOMETRIA TESTICULAR DE BOVINOS MESTIÇOS JOVENS SUBMETIDOS A DIFERENTES ESTRATÉGIAS DE SUPLEMENTAÇÃO ENERGÉTICA DE PASTAGEM DE Brachiaria Brizantha
}

\author{
Pedro Leonardo de Paula Rezende, ${ }^{1}$ João Restle, ${ }^{2}$ João Teodoro Pádua, ${ }^{2}$ \\ Juliano José de Resende Fernandes, ${ }^{2}$ Marcondes Dias de Freitas Neto ${ }^{3}$ e Bruno Duarte Alves Fortes ${ }^{3}$
}

\author{
1. Pós-graduação em Ciência Animal, Escola de Veterinária, Universidade Federal de Goiás. \\ E-mail: peleonardo@hotmail.com \\ 2. Professores doutores da Escola de Veterinária da UFG \\ 3. Pós-graduandos em Ciência Animal, EV/UFG.
}

RESUMO

Objetivou-se com este trabalho correlacionar as medidas testiculares e o ganho em peso, bem como as possíveis influências do nível alimentar sobre a morfometria dos testículos de 32 bovinos mestiços Holandês/Zebu, em fase de desenvolvimento sexual, mantidos em pastagem de Brachiaria brizantha submetida a dois níveis de suplementação energética, médio e alto, correspondendo ao fornecimento de suplemento em quantidade equivalente a $0,5 \%$ e 1,0\% do PV (TM e TA), respectivamente, durante a segunda metade do período de chuvas. Avaliaram-se o crescimento do perímetro escrotal in vivo e as medidas finais da porção glandular dos testículos em função do perímetro, comprimento, largura, volume, peso e forma. Os coeficientes de correlação entre as medidas testiculares e o ganho em peso foram moderadamente positivos, variando entre 0,12 e 0,32 . A análise de frequência demonstrou que prevaleceram os testículos de formato longo em ambos os tratamentos, respectivamente com $65 \%$ e $54 \%$ para TM e TA. Observou-se efeito significativo $(\mathrm{p}<0,05)$ do sistema alimentar sobre o ganho em perímetro escrotal in vivo em favor do grupo de alto nível de suplementação (TA), que ganhou $5,93 \mathrm{~cm}$ versus 3,71 $\mathrm{cm}$ do grupo TM. Não foi observado efeito significativo $(\mathrm{P}>0,05)$ do nível alimentar sobre as medidas glandulares dos testículos. Concluiu-se que estas características são determinadas pelo estádio de desenvolvimento sexual e não pelo nível alimentar e que as medidas testiculares não devem ser utilizadas isoladamente como critério de estimativa do desempenho de mestiços jovens.

PALAVRAS-CHAVES: Desempenho, perímetro escrotal, perímetro testicular, testosterona.

\section{ABSTRACT}

\section{TESTICULAR MORPHOMETRY OF CROSSBRED YOUNG BULLS SUBMITTED TO DIFFERENT STRATEGIES OF ENER- GETIC SUPPLEMENTATION OF Brachiaria brizantha PASTURE}

The objective of this study was to correlate the testicular measurements and weight gain, as well as the possible influence of the feeding level on the morphometry of the testicles of 32 crossbred Holstein/Zebu, in sexual development process, kept in Brachiaria brizantha pasture submitted to two levels of energy supplementation $(0.5 \%$ and $1.0 \%$ of $\mathrm{LW}, \mathrm{TM}$ and $\mathrm{TH})$ during the second half of the rainy season. In vivo growth of scrotal perimeter and the final measures of the glandular portion of the testicles according to the perimeter, length, width, volume, weight and shape were evaluated. The correlation coefficients between the testicular measures and weight gain were moderately positive, ranging between 0.12 and 0.32 . The frequency analysis showed that long testicles of long prevailed in both treatments, with respectively $65 \%$ and $54 \%$ for TM and TH. There was a significant effect $(\mathrm{p}<0.05)$ of the feed system on the in vivo gain of scrotal perimeter in favor of the high level of supplementation (TH), which gained $5.93 \mathrm{~cm}$ versus $3.71 \mathrm{~cm}$ of the TM group. There was no significant effect ( $>0.05$ ) of the feeding level on the testicles glandular measures. 
It was concluded that these characteristics are determined by the stage of sexual development and not by the feeding level and the testicular measures should not be used alone as a criterion for assessing the performance of crossbreed young bulls.

KEYWORDS: Performance, scrotal perimeter, testicular perimeter, testosterone.

\section{INTRODUÇÃO}

A qualidade das pastagens tropicais está sujeita a variações sazonais, tornando indispensável a adoção de tecnologias específicas para que o suprimento de nutrientes necessários ao desenvolvimento corporal e reprodutivo dos bovinos seja alcançado. A suplementação energético/proteica das pastagens em períodos considerados críticos permite que o animal tenha o aporte de nutrientes necessários para a manutenção das funções reprodutivas. No caso dos touros, a avaliação reprodutiva é comumente estimada pela avaliação morfométrica das gônadas que, segundo MARTIN et al. (1994), podem variar em função do manejo nutricional.

As características morfológicas e biométricas dos testículos constituem um dos principais parâmetros de seleção de animais nos programas de melhoramento genético de bovinos de corte, por serem de fácil obtenção, de alta repetibilidade e por estarem geneticamente correlacionadas com a libido (QUIRINO et al., 1999), qualidade seminal dos machos (VÁSQUEZ et al., 2003), peso corporal (QUIRINO et al., 1999), dentre outras características produtivas e, principalmente, reprodutivas.

Os aspectos biométricos dos testículos estão relacionados com a capacidade de produção hormonal (PINEDA et al., 2000) e os hormônios andrógenos produzidos nos testículos apresentam efeito no incremento do ganho em peso e eficiência alimentar (RESTLE et al., 2000). Segundo RESTLE et al. (2000), o efeito anabolizante dos hormônios testiculares está relacionado à maior eficiência de utilização dos nutrientes para ganho em peso e musculosidade. Entretanto, há necessidade de informações mais detalhadas sobre como as secreções hormonais e os parâmetros testiculares, avaliados nas fases iniciais de desenvolvimento sexual do animal, podem determinar as características que se referem ao crescimento e desempenho do animal.

Poucos estudos correlacionaram as variações da biometria testicular ao ganho em peso de bovinos, sendo que, na literatura disponível, existem poucos relatos abordando a influência do nível alimentar sobre os parâmetros testiculares de bovinos mestiços em fase de crescimento. Diante do exposto, objetivou-se com este estudo avaliar a influência do nível nutricional na fase de desenvolvimento sexual do animal, sobre as características morfológicas e biométricas dos testículos, bem como as correlações entre estas características e o desempenho de mestiços em pastagem de Brachiaria brizantha com diferentes estratégias de suplementação energética.

\section{MATERIAL E MÉTODOS}

O experimento foi desenvolvido de 23 de fevereiro a 8 de junho de 2008, correspondendo à segunda metade do período de chuvas, em área pertencente à Universidade Federal de Goiás (UFG), localizada no município de Goiânia, GO, com altitude de 771 $\mathrm{m}$, latitude $16^{\circ} 36^{\prime}$ Sul e longitude $49^{\circ} 15^{\prime}$ Oeste. Os índices meteorológicos de precipitação acumulada, temperatura e a umidade relativa do ar estão apresentados na Tabela 1.

TABELA 1. Dados meteorológicos do período experimental

\begin{tabular}{lccccc}
\hline & & & Meses & & \\
\hline & Fevereiro & Março & Abril & Maio & Junho \\
\hline Precipitação* & 141,26 & 235,34 & 126,84 & 166,4 & 0 \\
${ }^{1}$ Temp. ** & 23,4 & 23 & 23,4 & 20,7 & 21,2 \\
${ }^{2}$ UR** $^{*}$ & 86 & 85 & 85 & 69 & 61 \\
\hline
\end{tabular}

* Acumulado no período experimental de 21 dias (mm); **Média diária do período experimental de 21 dias; ${ }^{1}$ Temperatura $\left({ }^{\circ} \mathrm{C}\right) ;{ }^{2}$ Umidade relativa do ar (\%).

Fonte: Estação Evaporimétrica de Goiânia, 2008. 
Avaliaram-se as formas e a biometria dos testículos esquerdo e direito de 32 bovinos mestiços Holandês/Zebu oriundos do mesmo rebanho, com dez meses de idade, peso médio de $118,9 \pm 19,6 \mathrm{~kg}$ no início do experimento. Os animais foram mantidos em pastagem de Brachiaria brizantha com dois níveis de suplementação energética durante 126 dias.

O sistema de pastejo foi contínuo de lotação fixa, com carga animal média de $313,6 \mathrm{~kg}$ de peso vivo/ hectare (ha). Dividiu-se a área experimental em dois módulos de 8,5 hectares (ha), totalizando 17 ha, com disponibilidade de forragem (DF) média de $3.356 \mathrm{Kg}$ de matéria seca (MS)/ha. Coletaram-se as amostras de forragem aparentemente consumida por intermédio da técnica de simulação de pastejo (GIBB \& TREACHER, 1976), periodicamente, a cada 21 dias, visando coletar material semelhante ao consumido pelo animal.
As amostras foram secas em estufa de ventilação forçada a $65^{\circ} \mathrm{C}$, moídas em moinho tipo Willey com peneira de $5 \mathrm{~mm}$, acondicionadas em sacos plásticos e identificadas para posteriores análises bromatológicas. Estimou-se o percentual de proteína bruta (PB) da pastagem em aparelho de destilação a vapor micro-Kjedahl pelo teor de nitrogênio, utilizando-se o fator de conversão 6,25, conforme AOAC (1995). O percentual de fibra em detergente neutro (FDN) e fibra em detergente ácido (FDA) foi determinado por análise não sequencial, segundo metodologia de VAN SOEST adaptada por MOORE et al. (1987). Procedeu-se às análises dos teores de extrato etéreo (EE) e cinzas conforme metodologias descritas por SILVA \& QUEIROZ, (2002) como demonstrado na Tabela 2.

TABELA 2. Análise bromatológica das amostras de pastagem de Brachiaria brizantha aparentemente consumida

\begin{tabular}{lccccc}
\hline & \multicolumn{5}{c}{ Meses } \\
\hline MS & Fevereiro & Março & Abril & Maio & Junho \\
PB & 32,20 & 32,49 & 39,70 & 39,21 & 42,41 \\
EE & 8,77 & 10,19 & 9,38 & 7,15 & 6,94 \\
FDA & 1,50 & 1,66 & 1,50 & 1,41 & 1,31 \\
FDN & 37,08 & 37,99 & 39,84 & 40,69 & 42,23 \\
Cinzas & 65,87 & 64,48 & 69,51 & 69,96 & 74,64 \\
\hline
\end{tabular}

Matéria seca (MS), proteína bruta (PB), extrato estéreo (EE), fibra em detergente ácido (FDA), fibra em detergente neutro (FDN).

Para o ensaio de alimentação, distribuíram-se os animais ao acaso em dois tratamentos, recebendo nível de suplementação alto e médio (TA e TM), pelo fornecimento de $1,0 \%$ e $0,5 \%$ do peso vivo (PV) em MS de suplemento energético, respectivamente. O suplemento utilizado foi o grão de milho triturado finamente, acrescido de mistura mineral, conforme exigências sugeridas pelo NRC (1996), fornecido diariamente em cochos de suplementação, duas vezes, às 8 e às 17 horas.

$\mathrm{O}$ fornecimento do suplemento em função do PV dos animais era ajustado com base em pesagens periódicas dos animais de 21 dias, após jejum de sólidos de 12 horas. Na mesma ocasião, realizaram-se as mensurações de perímetro escrotal $(\mathrm{PE})$ in vivo. A medida foi tomada em brete de contenção, na posição de maior envergadura do escroto, utilizando-se fita métrica com escala de 0,001 metros. Após os 126 dias de alimentação, foram realizadas as demais avaliações morfométricas obtidas apenas na porção glandular de ambas as gônadas separadamente após a castração, dissecação e identificação dos testículos esquerdos e direitos.

Para a mensuração do comprimento, considerouse a porção glandular de ambos os testículos, excluindo a cauda dos epidídimos no sentido dorsoventral com auxílio de paquímetro. A largura foi obtida na região mediana de cada testículo no sentido lateromedial, também com auxílio de paquímetro. Para o cálculo 
do volume, adotou-se a fórmula do cilindro, a qual também foi usada por FIELDS et al. (1979), volume $=2\left[\left(\mathrm{r}^{2}\right) \times \pi \times \mathrm{h}\right]$, em que: $\mathrm{r}=$ raio calculado a partir da largura (largura/2), $\mathrm{h}=$ comprimento ou altura, $\pi$ $(\mathrm{Pi})=3,14$.

Para a determinação da forma testicular, utilizouse a metodologia descrita por BAILEY et al. (1996), que classificam o formato, de acordo com a razão da largura/comprimento, em cinco classes. Na classe 1, a razão largura/comprimento é menor ou igual a 0,5 , o que classifica o testículo como longo. Na classe 2, testículo longo-moderado, a razão encontra-se entre 0,510 e 0,625 . Na classe 3, moderado-oval, a razão largura/comprimento está entre 0,626 e 0,750 . Na classe 4, oval-esférico, a razão é de 0,751 a 0,875 . Na classe 5, com testículos classificados como esféricos, a razão largura/comprimento é maior que 0,875 .

Foram ainda considerados, para efeito de análise, o peso vivo final, obtido após os 126 dias de experimento, o ganho em peso médio diário (GMD), obtido pela diferença entre o peso final e inicial dividido pelo número de dias, e o ganho em peso total, obtido pela diferença entre o peso final e inicial.

As variáveis relativas ao efeito do nível de suplementação sobre os parâmetros testiculares foram analisadas em delineamento inteiramente casualizado $\mathrm{e}$ submetidas à análise segundo o modelo matemático, $\mathrm{Y}_{\mathrm{ik}}$ $=\mu+\mathrm{a}_{\mathrm{i}(1 ; 2)}+\mathrm{E}_{\mathrm{ik},}$ em que, $\mathrm{Y}_{\mathrm{ik}}=$ observações da variável dependente correspondente ao nível de suplementação i e repetição $\mathrm{k} ; \mu=$ média de todas as observações; $\mathrm{a}_{\mathrm{i}}=$ efeito do i nível de suplementação, sendo 1 e $2=0,5$ e $1,0 \%$ do PV respectivamente; $\mathrm{E}_{\mathrm{ik}}=$ erro experimental referente à observação do nível de suplementação i e repetição $\mathrm{k}$.

Efetuaram-se as análises com o auxílio do software estatístico SAS ${ }^{\circledR}$ versão 9.0 (SAS, 2002). Foram realizadas comparações de médias pelo teste $t$, admitindo-se 5\% como o nível de significância máximo das análises. Realizaram-se ainda análises de frequência, regressão linear e correlações de Pearson.

\section{RESULTADOS E DISCUSSÃO}

A Figura 1 ilustra a evolução das medidas de $\mathrm{PE}$ in vivo. Não foi observada diferença significativa $(\mathrm{P}>0,05)$ entre os tratamentos quando avaliado o perímetro testicular final da porção glandular dos testículos após os 126 dias de alimentação, entretanto, verificou-se efeito significativo $(p<0,05)$ quando esta variável foi estudada in vivo em função do crescimento de perímetro da bolsa escrotal (perímetro final - perímetro inicial). Os animais do grupo TA ganharam 5,93 cm versus 3,71 do grupo TM.

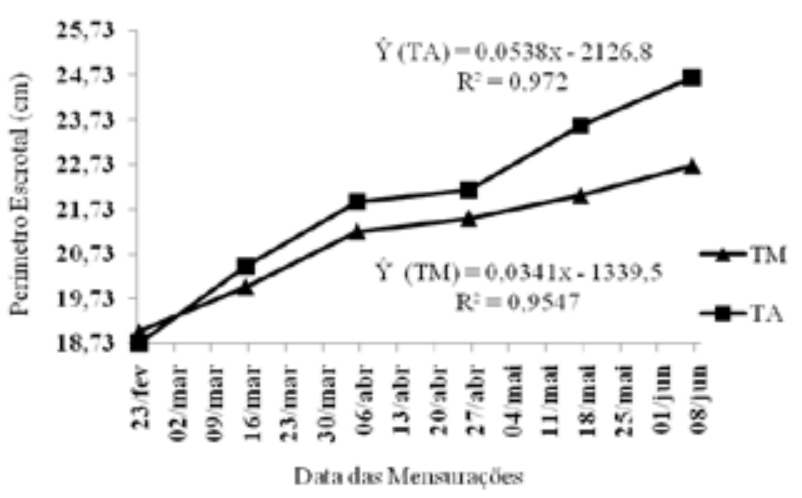

FIGURA 1. Evolução das medidas de perímetro escrotal (cm) de mestiços em diferentes estratégias de suplementação.

Nos animais do grupo TA, o crescimento maior de perímetro escrotal, em comparação ao grupo TM, provavelmente, ocorreu em função do maior aporte de nutrientes resultante da ingestão de energia proporcionada pelo nível de suplementação alto. Estes resultados estão de acordo VALE FILHO et al. (2003), que observaram que o manejo alimentar exerceu influência no crescimento de perímetro escrotal de touros da raça Tabapuã aos dois anos de idade divididos em três estratégias alimentares. O efeito da nutrição sobre o desenvolvimento testicular, principalmente o perímetro, foi estudado por SILVA et al. (2002). Esses autores relataram que a variação nutricional representada pela maior ingestão de nutrientes influenciou o crescimento testicular. Vale ressaltar que, segundo VALE FILHO et al. (2003), o perímetro escrotal não é a medida mais acurada, pois leva em consideração outros tecidos (conjuntivo, epitelial, pêlos), que superestimam esta avaliação.

Os valores de peso, comprimento, largura, perímetro, e volume da porção glandular dos testículos, obtidos após os 126 dias de alimentação, são apresentados na Tabela 3. Não houve diferença $(\mathrm{P}>0,05)$ entre as mensurações dos testículos direitos e esquerdos, $\mathrm{o}$ que evidenciou a simetria dos testículos. 
TABELA 3. Peso $(\mathrm{kg})$, comprimento $(\mathrm{cm})$, largura $(\mathrm{cm})$, perímetro $(\mathrm{cm})$, e volume $\left(\mathrm{cm}^{3}\right)$ da porção glandular dos testículos de bovinos mestiços submetidos a diferentes estratégias de suplementação

\begin{tabular}{lccccc}
\hline \multirow{2}{*}{ Medidas } & \multicolumn{3}{c}{ TM } & \multicolumn{2}{c}{ TA } \\
\cline { 2 - 4 } & Média & Desvio-padrão & Média & Desvio-padrão & 0,7891 \\
\hline PD & 0,15 & $\pm 0,05$ & 0,16 & $\pm 0,05$ & 0,5461 \\
PE & 0,13 & $\pm 0,04$ & 0,14 & $\pm 0,05$ & 0,7731 \\
CoD & 9,27 & $\pm 1,53$ & 9,09 & $\pm 1,37$ & 0,8666 \\
CoE & 8,59 & $\pm 1,30$ & 8,50 & $\pm 1,20$ & 0,7362 \\
PerD & 13,90 & $\pm 2,57$ & 14,27 & $\pm 2,41$ & 0,6055 \\
PerE & 13,22 & $\pm 2,28$ & 13,77 & $\pm 2,58$ & 0,7392 \\
LD & 4,43 & $\pm 0,82$ & 4,54 & $\pm 0,76$ & 0,6078 \\
LE & 4,21 & $\pm 0,72$ & 4,38 & $\pm 0,82$ & 0,9637 \\
VD & 308,79 & $\pm 156,02$ & 311,65 & $\pm 134,03$ & 0,7185 \\
VE & 254,86 & $\pm 117,60$ & 274,30 & $\pm 131,37$ & \\
\hline
\end{tabular}

PD (peso do testículo direito); PE (peso do testículo esquerdo); CoD (comprimento do testículo direito); CoE (comprimento do testículo esquerdo) PerD (perímetro do testículo direito); PerE (perímetro do testículo esquerdo); LD (largura do testículo direito); LE (largura do testículo esquerdo) VD (volume do testículo direito); VE (volume do testículo esquerdo); TM (médio nível de suplementação); TA (alto nível de suplementação); Pr > t (nível de significância).

Os valores de biometria testicular não foram influenciados pelos tratamentos alimentares $(\mathrm{P}>0,05)$ em nenhum dos parâmetros avaliados na porção glandular das gônadas direitas e esquerdas, provavelmente em função da idade dos animais. $O$ crescimento não significativo das medidas das gônadas entre dez e doze meses de idade indica que o processo de proliferação das células germinativas encontrava-se na fase inicial, com reduzida influência sobre a estrutura e diâmetro dos túbulos seminíferos. Em animais de subespécie Bos taurus taurus, as fases iniciais da espermatogênese estão associadas a variações muito reduzidas nas medidas testiculares (CURTIS \& AMANN, 1981).
RESTLE et al. (1999) relatam que os órgãos genitais têm prioridade na utilização dos nutrientes nas fases de desenvolvimento sexual. Esta afirmação também explicaria o fato de as medidas finais da porção glandular dos testículos dos diferentes tratamentos serem semelhantes, independente do nível alimentar.

$\mathrm{Na}$ classificação do formato testicular dos animais estudados prevaleceram os testículos longos em ambos os tratamentos (65 e 54\%), seguidos pelos longomoderados (35 e 37\%) para TM e TA, respectivamente (Tabela 4).

TABELA 4. Frequência das formas testiculares de mestiços submetidos a diferentes estratégias de suplementação de pastagem de Brachiaria brizantha

\begin{tabular}{lccccc}
\hline & Longo & Longo-moderado & Moderado-oval & Oval-esférico & Esférico \\
\hline TM & $65,0 \%$ & $35,0 \%$ & $0,0 \%$ & $0,0 \%$ & $0,0 \%$ \\
TA & $54,1 \%$ & $37,5 \%$ & $4,1 \%$ & $0,0 \%$ & $0,0 \%$ \\
\hline
\end{tabular}

TM (médio nível de suplementação); TA (alto nível de suplementação)

Resultados semelhantes foram observados por TORRES-JÚNIOR \& HENRY (2003), ao avaliarem o formato testicular de touros cruzados Holandês/Zebu. Os autores observaram maior frequência do formato testicular longo e longo-moderado em todas as idades. Em experimentos envolvendo touros da raça Nelore de dezoito meses de idade mantidos em pastagem tropical, prevaleceram formas intermediárias entre longo e esférico com 70,3\% (PINHO et al., 2001). GUIMARÃES et al. (2003), avaliando o formato testicular em touros da raça Nelore confinados e abatidos aos 22 meses de idade, constataram que os formatos testiculares longo 
e longo-moderado representavam $91,36 \%$ dos animais avaliados.

UNANIAN et al. (2000), analisando a distribuição das formas testiculares nas classes de idade, observaram que, com o aumento da idade, o formato dos testículos vai se modificando, tornando-se gradativamente mais ovalado. Esses mesmos autores relataram a predominância das formas alongadas e a ausência da forma esférica, assim como verificado neste estudo. BAILEY et al. (1996) observaram que animais com testículos mais alongados apresentavam maior concentração de espermatozoides no ejaculado que aqueles de formato testicular mais esférico.

Alterações nas formas dos testículos foram relatadas por UNANIAN et al. (2000). Esses autores ressaltaram a importância de mais estudos sobre modificações neste parâmetro em função da idade e manejo alimentar, uma vez que não há relatos semelhantes na literatura, e mudanças nas formas testiculares poderiam prejudicar os resultados de avaliações genéticas baseadas na biometria testicular.

PINHO et al. (2001) observaram que a relação comprimento-diâmetro dos testículos não apresentou variações entre dez e doze meses, mas, a partir dessa idade, aumentou significativamente entre doze e dezessete meses, evidenciando que há maior crescimento do comprimento testicular com relação à largura durante a pré-puberdade, o qual coincide com o aumento na secreção basal de testosterona.

Observa-se, na Tabela 5, que todas as medidas testiculares foram correlacionadas entre si. Houve correlação positiva de moderada intensidade e baixa significância $(\mathrm{P}>0,05)$ entre o GMD e as medidas testiculares com coeficientes variando entre $0,25 \mathrm{e}$ 0,32 . VALENTIM et al. (2002), estudando as medidas testiculares de bovinos jovens, obtiveram resultados semelhantes de correlação entre GMD e PE. Esses autores relataram que os coeficientes indicariam que parte dos genes envolvidos na expressão dessas características é comum. BOURDON \& BRINKS (1986), trabalhando com animais europeus de idade média de um ano e amplitude inferior a cem dias, também encontraram magnitudes de correlação semelhantes entre medidas testiculares e GMD que variaram de 0,26 a 0,43. MOURA et al. (2002) observaram que animais com maior peso de carcaça também tiveram maior peso testicular e epididimário.

Os resultados do presente estudo sugerem que apenas as medidas testiculares não representam boa ferramenta para estimativas de desempenho em sistemas de suplementação a pasto de animais mestiços em idade pré-púbere. Após a puberdade, há ainda crescimento contínuo das medidas testiculares e, como nesta fase não há mais proliferação das células de Sertoli (PINHO et al., 2001), este crescimento é consequência do aumento da população de células germinativas no interior dos túbulos seminíferos. Segundo EVERLING et al. (2001), não são esperadas altas respostas correlacionadas para as características de crescimento de efeito direto, quando o perímetro escrotal for usado como critério único de seleção, em consequência da correlação positiva, no entanto, de baixa magnitude.

TABELA 5. Coeficientes de correlação de Pearson entre as medidas da porção glandular dos testículos e ganho em peso médio diário de novilhos mestiços

\begin{tabular}{|c|c|c|c|c|c|c|c|c|c|c|}
\hline & $\mathrm{PE}$ & VD & VE & $\mathrm{CiD}$ & $\mathrm{CiE}$ & $\mathrm{CoD}$ & $\mathrm{CoE}$ & LD & LE & GMD \\
\hline$\overline{\mathrm{PD}}$ & 0,89 & 0,97 & 0,86 & 0,96 & 0,88 & 0,87 & 0,72 & 0,96 & 0,88 & $* 0,25$ \\
\hline PE & & 0,87 & 0,97 & 0,84 & 0,96 & 0,84 & 0,83 & 0,84 & 0,96 & $* 0,26$ \\
\hline VD & & & 0,85 & 0,97 & 0,87 & 0,87 & 0,70 & 0,97 & 0,87 & $* 0,27$ \\
\hline VE & & & & 0,83 & 0,96 & 0,80 & 0,86 & 0,83 & 0,96 & $* 0,31$ \\
\hline PerD & & & & & 0,87 & 0,78 & 0,66 & 0,99 & 0,87 & $* 0,30$ \\
\hline PerE & & & & & & 0,82 & 0,75 & 0,87 & 0,99 & $* 0,32$ \\
\hline CoD & & & & & & & 0,74 & 0,78 & 0,82 & $* 0,11$ \\
\hline $\mathrm{CoE}$ & & & & & & & & 0,66 & 0,75 & $* 0,12$ \\
\hline LD & & & & & & & & & 0,87 & $* 0,30$ \\
\hline LE & & & & & & & & & & $* 0,32$ \\
\hline
\end{tabular}

PD (peso do testículo direito); PE (peso do testículo esquerdo); CoD (comprimento do testículo direito); CoE (comprimento do testículo esquerdo); PerD (perímetro do testículo direito); PerE (perímetro do testículo esquerdo); LD (largura do testículo direito); LE (largura do testículo esquerdo); VD (volume do testículo direito); VE (volume do testículo esquerdo); TM (médio nível de suplementação); TA (alto nível de suplementação); *probabilidade (P>0,05). 
O processo contínuo de crescimento das gônadas coincide com a elevação nos níveis de testosterona até os dezoito meses de idade desencadeando a puberdade (CURTIS \& AMANN, 1981). Esses mesmos autores mencionam que, em touros da raça Holandês, o comprimento dos túbulos seminíferos aumenta significativamente entre três meses ( $830 \pm 73 \mathrm{~m} /$ testículo) e sete meses $(2.010 \pm 128 \mathrm{~m} /$ testículo), ou seja, durante a fase de pré-puberdade, quando ocorre a elevação na síntese de testosterona. Esse possível aumento dos níveis basais de testosterona proporcionado pelo crescimento de PE nesta fase não significou aumento do desempenho dos animais de ambos os tratamentos do presente estudo, como demonstrado nas Figuras 2 e 3.

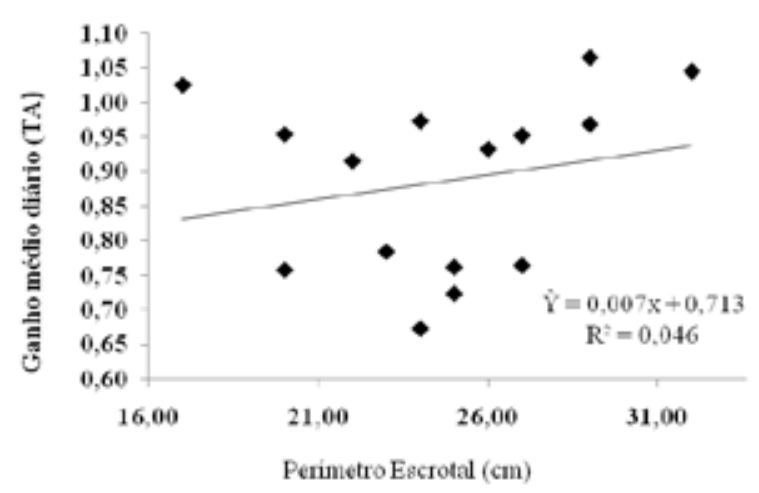

FIGURA 2. Regressão linear entre perímetro escrotal (cm) e ganho em peso médio diário $(\mathrm{kg} /$ dia) de mestiços submetidos ao nível alto de suplementação em pastagem de Brachiaria brizantha.

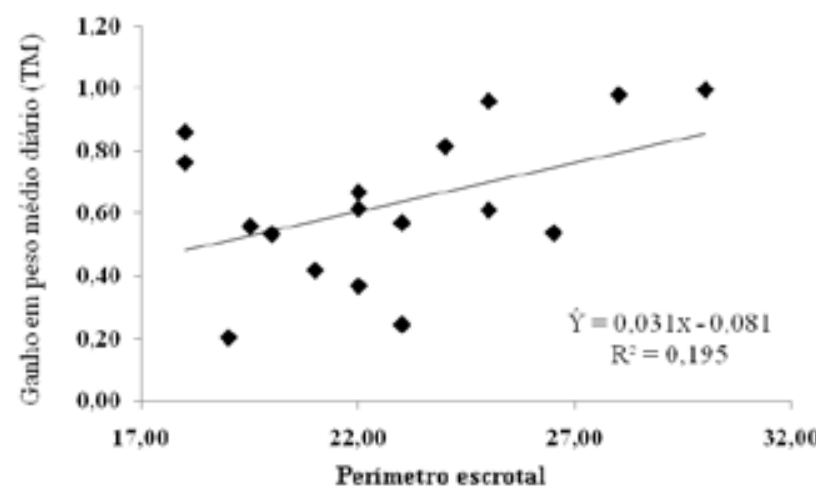

FIGURA 3. Regressão linear entre perímetro escrotal (cm) e ganho em peso médio diário $(\mathrm{kg} / \mathrm{dia})$ de mestiços submetidos ao nível médio de suplementação em pastagem de Brachiaria brizantha.

\section{CONCLUSÕES}

As diferentes estratégias de suplementação energética de pastagem de Brachiaria brizantha não influenciaram o peso, as medidas e as formas dos testículos de mestiços jovens evidenciando que, em animais em fase de crescimento, essas características são determinadas pelo estádio de desenvolvimento sexual e não pelo nível alimentar.

A biometria testicular não esteve correlacionada com o ganho em peso médio diário, mostrando que essas características não devem ser utilizadas isoladamente como critério de estimativa do desempenho de mestiços jovens em regime de suplementação energética de pastagem.

\section{REFERÊNCIAS}

ASSOCIATION OF OFFICIAL ANALYTICAL CHEMISTS AOAC. Official methods of analysis. Washington, DC, 1995. $1015 \mathrm{p}$.

BAILEY, T. L.; MONKE, D.; HUDSON, R. S.; WOLFE, D. F.; CARSON, R. L.; RIDDELL, M. G. Testicular shape and its relationship to sperm production in mature Holstein bulls. Theriogenology, v. 46, n. 3, p. 881-887, 1996.

BOURDON, R. M.; BRINKS, J. S. Scrotal circumference in yearling Hereford bulls: adjustment factors, herdabilities and genetic, environmental and phenotypic relationships with growth traits. Journal of Animal Science, v. 62 , p. 958-967, 1986.

CURTIS, B. K.; AMAN, R. P. Testicular development and establishment of spermatogenesis in Holstein bulls. Journal of Animal Science, v. 53, p. 1645-1658, 1981.

EVERLING, D. M.; FERREIRA, G. B. B.; RORATO, P. R. N. Estimativas de herdabilidade e correlação genética para características de crescimento na fase pré-desmama e medidas de perímetro escrotal ao sobreano em bovinos Angus-Nelore. Revista Brasileira de Zootecnia, v. 30, p. 2002-2008, 2001.

FIELDS, M. J.; BURNS, W. C.; WARNICK, A. C. Age, season and semen traits in young beef bulls. Journal of Animal Science, v. 48, p. 1299-1304, 1979.

GIBB, M. J.; TREACHER, T. T. The effect of herbage allowance on herbage intake and performance of lambs grazing perennial ryegrass and redclover swards. Journal of Agricultural Science, v. 86, p. $355-365,1976$.

GUIMARÃES, J. D.; VASCONCELOS, C. O. P.; GUIMARÃES, S. E. F.; COSTA, E. P.; MIRANDA NETO, T. Biometria testicular em bovinos da raça Nelore, dos 20 aos 22 meses de idade. Revista Brasileira de Reprodução Animal, v. 27, n. 2, p.173174, 2003. 
MARTIN, G. B.; TJONDRONEGORO, S.; BLACKBERRY, M. A. Effects of nutrition on testicular size and the concentrations of gonadotrophins, testosterone and inhibin in plasma of mature male sheep. Journal of Reproduction and Fertility, v. 101, n. 1, p. 121-128, 1994.

MOORE, J. A.; POORE, M. H.; WINGH, R. S. Standard operation procedures in situ NDF determinations. Journal of Animal Science, v. 65, p. 487, 1987.

MOURA, A. A. A.; RODRIGUES, G. C.; MARTINS FILHO, R. Desenvolvimento ponderal e testicular, concentrações periféricas de testosterona e características de abate em touros da raça Nelore. Revista Brasileira de Zootecnia, v. 31, n. 2, p. 934-943, 2002.

NRC - National Research Council. Nutrient requirement of beef cattles. 7. ed. Washington: National Academy, 1996. 242 p.

PINEDA, N. R.; FONSECA, V. O.; ALBUQUERQUE, L. G. Preliminar study of influence of scrotal circumference upon libido and seminal characteristics in young Nelore bulls. Arquivo Brasileiro de Medicina Veterinária e Zootecnia, v. 52, p. 69-75, 2000.

PINHO, T. G.; NOGUEIRA, L.A. G.; PINTO, P.A.; ZAMBORLINI, L.; GILARDI, S.; CALDAS, M.; SOUZA, R. M. Características seminais de touros jovens Nelore (Bos taurus indicus) de acordo com a biometria e morfologia testicular. Revista Brasileira de Reprodução Animal, v. 25, n. 2, p. 187-189, 2001.

QUIRINO, C. R.; BERGMANN, J. A. G. Heritability of scrotal circumference adjusted and unadjusted for body weight in Nellore bulls using ani and bivariate animal models. Theriogenology, v. 48, n. 7, p. 1398-1396, 1999.

RESTLE, J.; FILHO, D. C. A.; FATURI, C. Desempenho na fase de crescimento de machos bovinos inteiros ou castrados de diferentes grupos genéticos. Revista Brasileira de Zootecnia, v. 29, n. 4, p. 1036-1043, 2000.
SAS INSTITUTE. SAS/STAT user's guide: statistics. 6. ed. Version 8. Cary, NC, 2002. v. 2, 943 p.

SILVA, A. E. D. F.; UNANIAN, M. M.; CORDEIRO, C. M. T.; FREITAS, A. R. Relação da circunferência escrotal e parâmetros da qualidade do sêmen em touros da raça Nelore, PO. Revista Brasileira de Zootecnia, v. 31, n. 3, p. 1157-1165, 2002.

SILVA, D. J.; QUEIROZ, A. C. Análise de alimentos (métodos químicos e biológicos). 3. ed. Viçosa, MG: Universidade Federal de Viçosa, 2002. 235 p.

TORRES-JÚNIOR, J. R. S.; HENRY, M. Perfil biométrico testicular e puberdade seminal em touros da raça Guzerá (Bos taurus indicus): resultados preliminares. Revista Brasileira de Reprodução Animal, v. 27, n. 2, p. 304-305, 2003.

UNANIAN, M. M.; SILVA, A. E. D. F.; McMANUS, C.; CARDOSO, E. P. Características biométricas testiculares para avaliação de touros zebuínos da raça Nelore. Revista Brasileira de Zootecnia, v. 29, n. 1, p. 136-144, 2000.

VALE FILHO, V. R.; ANDRADE, V. J.; SALVADOR, D. F.; DIAS, J. C.; ABREU, J. J.; GRAÇA, D. S.; BERGMANN, J. A. G. Prevalência de tourinhos da raça Tabapuã precoces e super-precoces (um e dois anos de idade), com base no perfil andrológico, submetidos a dois manejos nutricionais, na região de Nanuque, MG. Revista Brasileira de Reprodução Animal, v. 27, n. 2, p. 178-180, 2003.

VALENTIM, R.; ARRUDA, R. P.; BARNABE, R. C.; ALENCAR, M. M. Biometria testicular de touros Nelore (Bos taurus indicus) e touros cruzados Nelore-europeu (Bos taurus indicus x Bos taurus taurus) aos 20 e 24 meses de idade. Brazilian Journal of Veterinary Research and Animal Science, v. 39, n. 3, p. 113$120,2002$.

VÁSQUEZ, L.; VERA O.; ARANGO J. Testicular growth and semen quality in peripuberal Brahman bulls. Livestock Research for Rural Development, v. 15, 2003. 